\title{
Reviewers for Volume 24
}

An asterisk denotes a member of the Editorial Board.

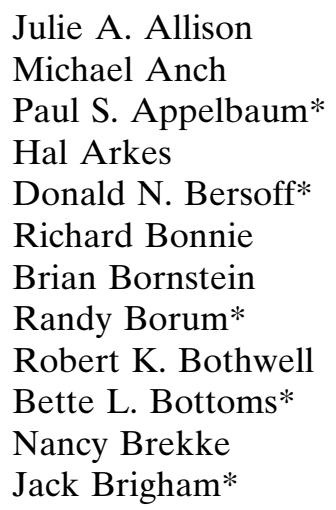

David Faigman*

Neal Feigenson

Robert Fein

Norman J. Finkel*

Robert P. Fisher

William Fisher

Louise F. Fitzgerald

Robyn Fivush

Diane Follingstad*

Patricia A. Frazier

Richard I. Frederick

Jonathon L. Freedman

Soloman M. Fulero*

Jeffrey Gfeller

James F. Gilsinan

Jonathan M. Golding*

Stephen L. Golding

Gail Goodman*

Jane Goodman-Delahunty*

Edith Greene*

Thomas Grisso*

Barbara Gutek*

Kevin Hamberger

Paul Handal

Valerie Hans*

Alan Harkness

Grant Harris

Stephen Hart

Reid Hastie

Jeffrey Haugaard*

Kirk Heilbrun*

Irwin A. Horowitz

Harmon M. Hosch

Larry Hueur

Elaine Jones 
Colleen Sinclair, Department of Psychology, University of Minnesota Allison Smith, Department of Psychology, University of Colorado at Colorado Springs

Samuel R. Sommers, Department of Psychology and School of Law, University of Michigan

Terri Stewart, Department of Psychology, University of Kentucky

Lisa Strohman, Law-Psychology Program, Hahnemann University

Lisa Strohman, School of Law, Villanova Law School

Laura Warren, Department of Psychology, Saint Louis University

Stephanie Weeks, Department of Psychology, North Carolina State University Ryan J. Winter, Department of Psychology, City University of New York 